\title{
RESIDENTIAL ARCHITECTURE: EVALUATION OF TENANTS' SATISFACTION IN PRIVATE CULTURE
}

\author{
LIUDMILA CAZACOVA ${ }^{1} \&$ BALKIZ YAPICIOGLU ${ }^{2}$ \\ ${ }^{1}$ American University of Ras Al Khaimah, United Arab Emirates \\ ${ }^{2}$ Arkin University of Creative Arts and Design, Cyprus
}

\begin{abstract}
This paper focuses on the significance of privacy in housing design for private cultures and analyses residential satisfaction of design. Furthermore, the paper presents the unique features of a traditional house in Islamic cultures, and the role it plays providing residents of these houses with the desired privacy along with the importance and the meaning of residential privacy in private cultures, and how the contemporary architecture respects the privacy achieved in the traditional Islamic housing. Mirbat town in the Sultanate of Oman is used as a case study for this research and builds on the authors' previous study of Mirbat's old and new residential quarters where the detailed study of the architecture of 102 traditional residences were conducted and assessed. Furthermore, two additional surveys of young and older residents (as focus groups) of traditional and contemporary housing in Mirbat were conducted to expand and strengthen the findings of the current research, which aimed to study residential satisfaction as it relates to different aspects of privacy and as a measure of evaluating residential quality. Through a comparison of old and new quarters of Mirbat, and traditional and contemporary residences, the authors expose the differences in design between the old and the new. Finally, the authors conclude that those unique features that were employed in traditional housing design are no longer employed in contemporary residences' design (or employed only as decorative elements) compromising the privacy of the residents.
\end{abstract}

Keywords: private cultures, privacy, residential architectural features, residential satisfaction.

\section{INTRODUCTION}

In private cultures such as in Arab Gulf countries and other Islamic cultures, the concept of privacy has always been of a primary consideration and traditional houses were built to adapt to the local natural habitat to satisfy societal and cultural values. Islamic architecture designates certain cultural norms [1], particularly its strong accent on the highly societally valued attribute of family privacy. As the home is considered a social unit whose structure cannot be disassociated from the family living inside it, Islamic architecture particularly prioritizes the human needs of safety and privacy. By designing from inside out and implementing a strong spatial hierarchy, traditional Islamic architecture satisfies inhabitants' desires for both privacy and social contact [2], [3].

This research presents the unique features of a traditional house in Islamic cultures and the role it plays in providing its residents with the desired privacy. It also explores the meaning residential privacy in private cultures has, and evaluates how much contemporary housing architecture respects the privacy achieved in the traditional Islamic housing using Mirbat as a case study. The research builds on the authors' previous study [4] of Mirbat's old and new residential quarters, and detailed study of 102 traditional residences. Mirbat, a defensive city of Dhofar region in the Sultanate of Oman, which is situated along the coast of the Indian Ocean, dates back to the fourth millennium BC. Formerly well known for exporting frankincense and Arabian horses, Mirbat currently exhibits a blend of old inhabited and/or abandoned stone houses designed in local Islamic style, and newly evolved modern structures. Through a comparison of old and new quarters of Mirbat and traditional and contemporary residences, the authors expose the differences in design 
between the old and the new, and how those unique features that were employed in traditional housing design are no longer employed in contemporary residences' design (or employed only as decorative elements) [5] compromising the privacy of the residents. Furthermore, two surveys were conducted using young and older residents (as focus groups) of traditional and contemporary housing in Mirbat. The surveys were conducted to expand and strengthen the study which aimed to study residential satisfaction as it relates to different aspects of privacy and as a measure of evaluating residential quality [6] and was executed through the self-assessment questionnaires.

The findings of this research show that the design of contemporary residences, in comparison to the traditional ones, do not contemplate privacy as first consideration and do not employ architectural design features that were culturally considered important for residents' safety and privacy provision. Additionally, the analysis of the surveys conducted among residents show that most of them, despite the age group, are dissatisfied with the design of their contemporary housing. As residential satisfaction is defined as indicator of inhabitants' perception of their quality of life [7], [8] this study concludes that the design of the contemporary housing in Mirbat does not meet the cultural expectations of the residents.

\section{THEORETICAL BACKGROUND}

A residence, a house is a place to settle and calm down, relax, and/or reside [9], a place, where residents spend most of their time [3]. Its primary purpose is to provide residents with a safe, comfortable, healthy and secure indoor environment in which they conduct their daily activities as well as social interactions [10]. Beyond the satisfaction of residents' basic needs, a house acts as a social control mechanism, which is strong in traditional cultures [11] and, therefore, should also satisfy residents' spiritual desires, as well as their lifestyles' cultural and religious aspects [3]. In other words, the image of an ideal home is constructed by peoples' goals for their residence, which must satisfy inhabitants' personal and cultural needs as dictated by their social backgrounds and lifestyles [12]. These aims were perfectly achieved by vernacular architecture, which is the art of constructing communities reflecting a society's inherent culture [13].

When examining housing design examples in various Islamic countries, certain spatial and layout similarities and features are evident [14]. For example, Nafeesi [2] and Poirier et al. [15] describe the traditional Gulf house as a unit with a high level of privacy, where bedrooms and family quarters are farthest away from the point of entry. An L-shaped entrance hall leading to the public portion of the house prevents the inhabitants from being viewed from outside. The inner courtyard, which is surrounded by rooms, forms a visually and physically protected outdoor space in which the residents can enjoy full freedom. Most of the windows face the inner courtyard; those that face the street, along with any terraces or balconies, are latticed or protected with mashrabiya screens (the Arabic term for a wood lattice screen used in the Middle East on windows, balconies, room dividers, etc. for privacy provision).

Similarly, in Malaysia, internal design, layout and features are also influenced by culture, particularly with regard to respect for the elderly and the elevated household position of women. As such, the house's public space - the reception hall - is used only by male visitors [16].

The configuration of Iranian houses [3] anticipates balance between hospitality, social contacts and the inhabitants' privacy. This balance is facilitated by the division of spaces into exterior (guests') and interior private rooms. The interior rooms are located to prevent outside observation and access, while the exterior rooms (vestibule and reception area) 
located at the entrance are used for male visitors only, and the inner courtyard formed by surrounding rooms provides a private area for the house's inhabitants.

In Yemen, the typical Shibam house [9] encompasses spaces such as the diwan (reception area and guests' rooms are used only on special occasions and by male visitors only), dining area, bedrooms, courtyard, balcony and rooftop terrace surrounded by high walls. The ground and first floors are dedicated to business and storage, the second is for women's activities and the third floor is for men's activities.

In Oman, the typical Dhofari dwelling, which houses the head of family with his wife or wives and their children, is distinguished by a reception room for male visitors (majlees) with a segregated entrance and adjacent bathroom. A separate entrance allows family members to access the house's private spaces, including the sallah (living room), kitchen, bedrooms and/or multipurpose rooms. The house's exterior design, which is influenced by military style, is distinguished by the contrasting features of massive walls with decorative roof stepped parapets and carved wooden doors/windows with mashrabiya screens [1], [4], [17].

Irrespective of cultural and national differences, a home is commonly defined as a physically bounded area where private and family lives develop [18], it refers to the desire to maintain solitude, isolation, anonymity, reserve and intimacy with friends and family. Furthermore, Article 8 of the European Convention on Human Rights [19] states that everyone has the right to respect for his private and family life, his home and correspondence. To assess the quality of housing design, residential satisfaction surveys are usually conducted. Residential satisfaction is an indicator of how the quality of residents' life is perceived by them and depends on expectations dictated by cultural norms [7], [20], [21]. Multiple variables such as functional suitability of the building (space utilization, physical condition, safety and statutory requirements), design and construction quality (services within the building), building serviceability (with respect to occupants' needs and provided facilities), environmental performance (indoor air quality, appearance and lighting, energy consumption, intrusion prevention and control), and post-occupancy evaluation (the building's technical, functional and behavioural aspects) [10], [22], [23] are used for determining residents satisfaction or dissatisfaction. Variables depend on the subject of study and the purpose of residential satisfaction evaluation. As for private cultures, privacy of residents is a main variable that assess the quality of the residential environment and how it impacts residents' comfort, security and mobility [7].

\section{METHODOLOGY}

The study is divided into four stages as shown in the research conceptual diagram given below (Fig. 1).

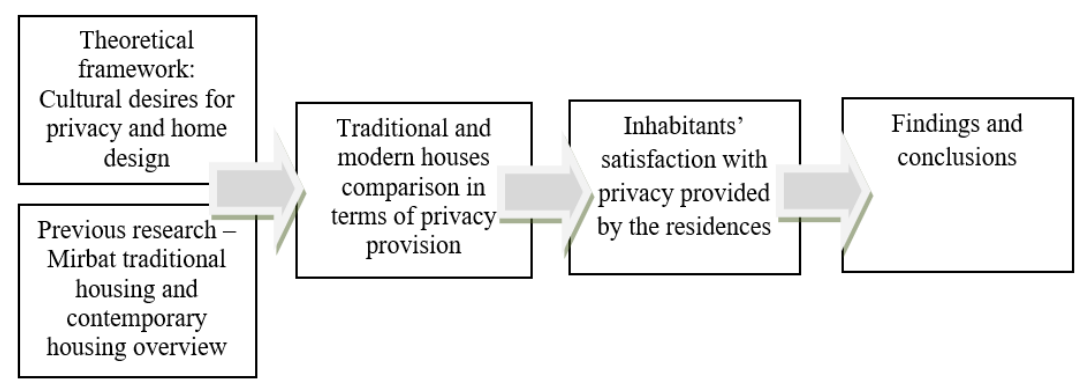

Figure 1: Research conceptual diagram. 
As previously mentioned, it builds on study of Mirbat traditional housing conducted by the authors in 2014 and theoretical study on privacy considerations in housing design for private cultures, followed by traditional and contemporary housing design comparison, survey and analyses of residents' satisfaction after which a conclusion is drawn.

To evaluate the effectiveness of Mirbati housing design as it relates to residents' privacy, two group administered surveys were conducted, for which, close ended, paperand-pencil based questionnaires were prepared. The surveys evaluated residents' satisfaction with the level of privacy of modern and traditional residences.

The first survey was conducted in Dhofar University's Department of Graphic Design and Interior Architecture (Oman) in November 17-22, 2017. The participants, who were volunteers, were restricted to female students pursuing bachelor's degrees (age group: 1925). In private cultures such as Dhofari (Muslim), privacy is an issue for a woman, and not for a man, the woman is requested to cover herself, thus no part of her body is exposed for men's observation, but only for women and family members. The questionnaires were distributed among students during break times and the participants were briefed regarding its purpose. Of 110 qualifying students in the department, 100 participated in the questionnaire survey, representing $47.6 \%$ of the total possible participant pool.

The second survey was conducted in the central area of Mirbat town, where the old (traditional) and new residences are mixed together. The survey started on 3rd March and ended 24th April 2018. The questionnaire was distributed to one hundred households where the recipients were 211 female inhabitants from the age of 35 and above. The data was systematized into column charts using Microsoft Office Excel 2013.

The first survey, conducted among young female at Dhofar University, is a nine-item questionnaire and considers the following dimensions: (1) usage of the courtyard; (2) reasons of not using the courtyard; (3) frequency of curtain usage; (4) reasons of windows curtaining; (5) usage of the roof terrace; (6) reasons of not using the roof terrace; (7) usage of balconies/terraces; (8) reasons of not using balconies/terraces and (9) satisfaction with the privacy of the residence. The second survey, conducted among elderly female generation in Mirbat town, is similar to the first one, but contains additional questions concerning age and type of the residence (modern/traditional).

\section{RESEARCH BACKGROUND: MIRBAT OLD TOWN}

Authors' findings from previous study [4] along with theoretical work on homes, private cultures and residents' satisfaction, motivated the examination and comparison of old and modern Mirbat residences, specifically the analysis of those features that contribute to the facilitation of residents' privacy (Fig. 2).

\subsection{Old town area houses' design examination}

Traditional Arab cities are characterized by their organic spatial patterns with minimal open spaces and highly dense housing arrangements [24]. Subsequently, Mirbat's old town exhibits an organic, non-geometric and spontaneous scheme, with unordered arrangements of districts around the city centre comprising the castle, mosque and marketplace. The urban pattern, which follows the topography, is also organic, with irregular curved streets of varying lengths and widths. The area's traditional residences, built around one hundred years ago, are grouped together to form family residential quarters. The family quarter comprises several attached houses of different size and height built along the irregular, narrow dirt streets. Despite their different size, height and ownership, all residences bear common distinctive characteristics dictated by defensive city requirements, climate and inhabitants' lifestyles (Figs. 2 and 3) [4]. 


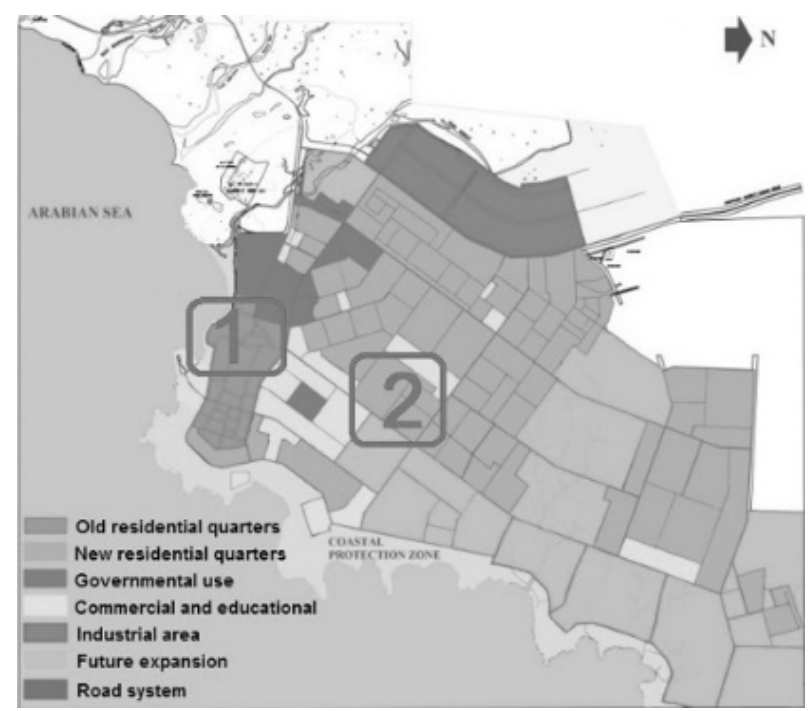

Figure 2: The two areas of Mirbat, featuring old (1) and new quarters (2), wherein the old area accommodates the old quarters with typical traditional and modern houses, while the new quarter accommodate newly designed residences.

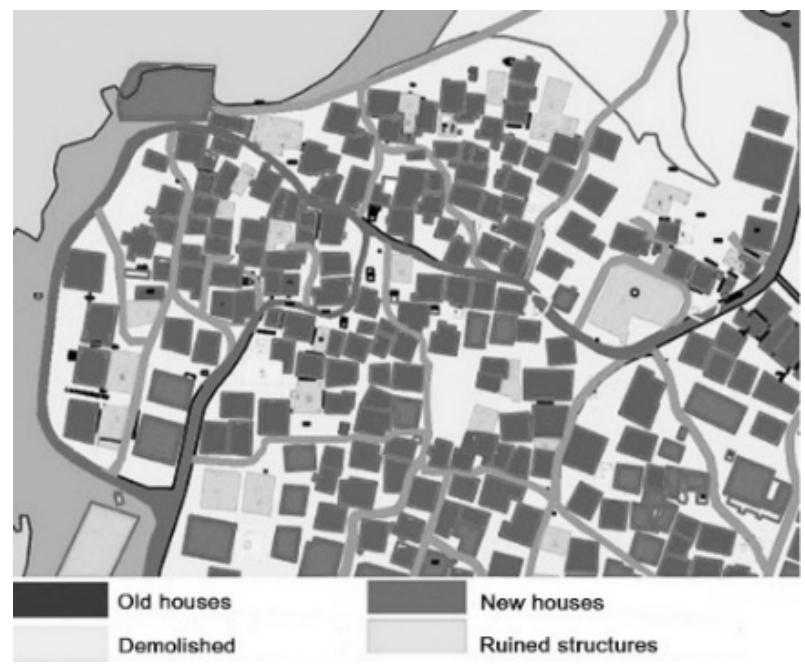

Figure 3: Mirbat old town's map.

The typical traditional Mirbati house is a medium-sized, two-storey building with a ground floor (bakhkhar), first floor (gharfat) and roof terrace (rawshan). The houses' sandycoloured façades (finished with limestone plaster (norah)) are characterized by asymmetry, absence of projections, minimal decorative elements, flat roofs, high parapets crowned with stepped merlons (mijmara), protruding roof drains made of palm tree trunks, and roof spouts. Stone benches line the perimeter. The beautifully carved wooden windows, which 
are mainly located on the upper level, are composed of two units: the outer fixed screen, and a segmented inner shutter. Each house contains a minimum of two types of doors (all wooden and richly carved): a large outer double door, and a smaller inner one. The doors are equipped with massive locks inside locks and one outside lock (Fig. 4) [4].

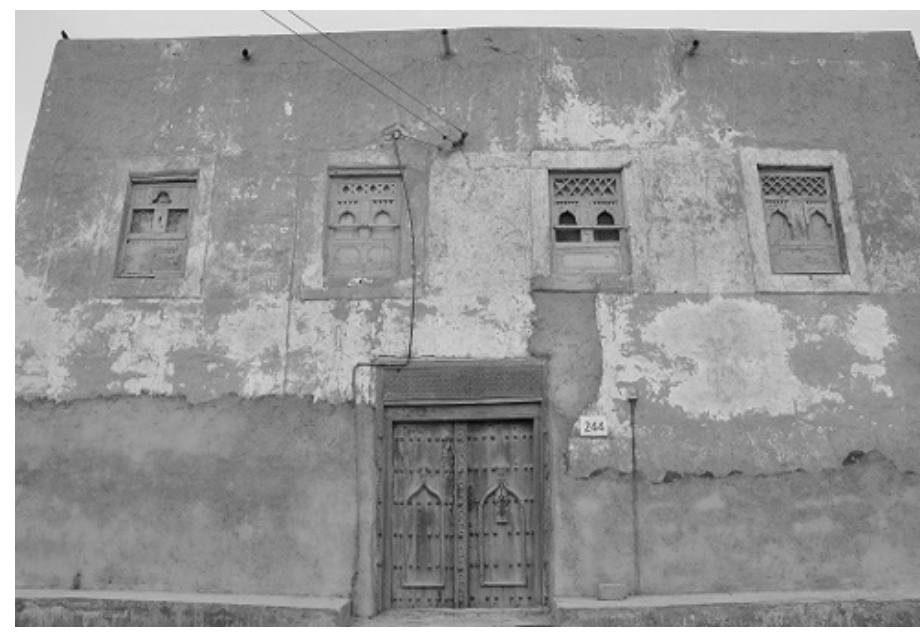

Figure 4: Typical traditional house located in the old town of Mirbat.

The houses' interior spaces are screened by a gallery that lines the inner courtyard, which maintains the privacy within the house. Both ground- and first-floor layouts observe a strict division of public, semi-private and private spaces. The ground floor encompasses a large room used as reception hall for male visitors only (majlees), and includes a segregated entrance, entrance hall with living room (sallah), multipurpose rooms (dahrizes), kitchen and storage. Sallah is usually used for family gathering, dinning and celebrations, while Dahriz is used for sleeping and as private living area for family members, though could be used by house visitors as well. On the upper level, there are more dahrizes, a roof terrace and a walled open-air toilet situated above the storage room. The interior spaces are lit and ventilated via courtyard-facing openings [4].

\subsection{New town area houses' design examination}

Mirbat's newest districts are arranged in a grid, with blocks of houses located along streets of regular length. Because the government allocates plots of land (usually $600 \mathrm{~m}^{2}$, except of those at the edge of the quarter $-700 \mathrm{~m}^{2}$ ) to inhabitants for house construction, residential blocks are of identical size, though might differ by shape (Fig. 5(a)) [25].

The modern Mirbati house is a generally medium-to-large, generally two-to-threestorey residence with an adjacent (or no) courtyard. The inner spaces are situated around a large interior sallah accessed through the adjacent entrance hall. The majlees, which is usually situated on the ground floor next to the main entrance, might have either a segregated or a shared access with the entrance hall. Beside the majlees and sallah, the ground floor also contains dahrizes, the kitchen and bathrooms. Family bedrooms are mainly located on upper floors, and the flat roof is used as terrace. Interior spaces are mainly lit through single-glazed windows located on the house's exterior walls (Fig. 5(b)). 


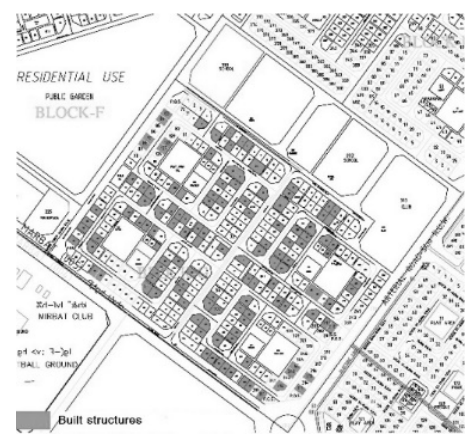

(a)

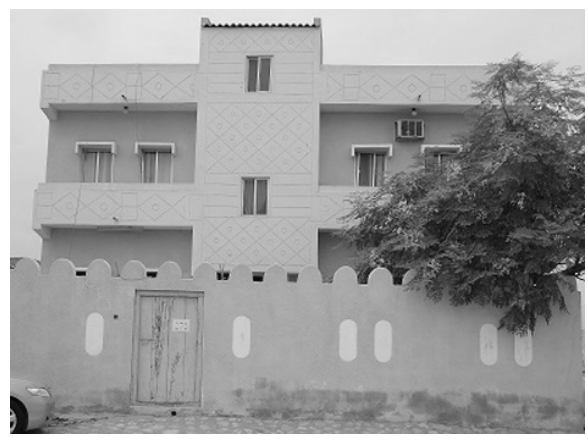

(b)

Figure 5: (a) Mirbat new town's quarters; and (b) Modern house situated in a new district of Mirbat town.

\subsection{Privacy comparison between traditional and modern residences' design}

This section evaluates Mirbat's traditional and modern houses in terms of privacy, particularly with regard to those features initially designed for safety provision, such as block type and layout, façade height and type, spatial and courtyard layout, window/door types and locations, and roof parapets, etc.

A comparison of the two Mirbati housing types indicates that both traditional and modern houses evince a strict spatial hierarchy (public, semiprivate and private) dictated by cultural concerns. However, most traditional house features generally facilitate privacy, while only some of modern house features accomplish the same.

In the old quarters, residential blocks are located randomly, and houses share walls or are positioned very close together. However, building heights are regular, which restricts the view from neighbouring houses to the inner courtyard and roof terrace, the latter of which is safeguarded by a high parapet. Each house's main street-facing façade accommodates rare upper-level windows; other walls are either shared or left blank. All windows (even those facing the courtyard) are screened from the out-side and shuttered from the inside. Multiple doors provide direct access to public spaces, and the entrance hall door, with its small opening, limits the view to the house's interior. Spaces located along the perimeter are accessed from the courtyard, which is protected by the house's walls. Such a layout permits multiple windows without compromising privacy requirements (Table 1).

In the new quarters, the residences are located at approximately similar distance to each other. While building heights are uniform, windows located on façades facing neigh-boring buildings allow observation of interior spaces. The windows (despite featuring reflective glass) are not screened and require thick curtains. The adjacent courtyard and balconies, when available, can be viewed from the upper floors of neighbouring residences. All of the modern house features listed above potentially compromise inhabitants' comfort and privacy (Table 1) and contradict local regulations (the architectural design of the building shall conform with the social norms of the Arab Muslim families in terms of the location of various parts of the residential unit such as windows, doors, screens, etc. for privacy provision) [25]. 
Table 1: Old and new houses' features relevance to the privacy provision.

\begin{tabular}{|c|c|c|c|c|}
\hline \multirow[b]{2}{*}{$\begin{array}{l}\text { Housing } \\
\text { features }\end{array}$} & \multicolumn{2}{|c|}{ Old quarters } & \multicolumn{2}{|c|}{ New quarters } \\
\hline & Description & $\begin{array}{l}\text { Privacy } \\
\text { provision }\end{array}$ & Description & $\begin{array}{l}\text { Privacy } \\
\text { provision }\end{array}$ \\
\hline Block types & $\begin{array}{l}\text { Irregular, shared } \\
\text { walls }\end{array}$ & Yes & $\begin{array}{l}\text { Regular, closely } \\
\text { located }\end{array}$ & No \\
\hline Heights & $1,1.5,2,2.5$ & Yes & 2,3 & Yes \\
\hline \multirow{3}{*}{ Façades } & Rare windows & Yes & Multiple windows & No \\
\hline & High roof parapet & Yes & High roof parapet & Yes \\
\hline & Roof spots & Yes & $\begin{array}{l}\text { Unscreened } \\
\text { balconies }\end{array}$ & No \\
\hline Window types & $\begin{array}{l}\text { Double: fixed outer } \\
\text { screen; inner shutters }\end{array}$ & Yes & Unscreened & No \\
\hline \multirow{3}{*}{$\begin{array}{l}\text { Window } \\
\text { location }\end{array}$} & $\begin{array}{l}\text { Street façade-upper } \\
\text { level }\end{array}$ & Yes & $\begin{array}{l}\text { Street façade-each } \\
\text { floor }\end{array}$ & No \\
\hline & $\begin{array}{l}\text { Other façades-no, } \\
\text { any }\end{array}$ & Yes & Other façades-each & \\
\hline & $\begin{array}{l}\text { Facing inner } \\
\text { courtyard }\end{array}$ & Yes & floor & No \\
\hline Door types & $\begin{array}{l}\text { Main-with small } \\
\text { opening }\end{array}$ & Yes & $\begin{array}{l}\text { Without any } \\
\text { opening }\end{array}$ & Yes \\
\hline Door location & Multiple & Yes & Maximum two & No \\
\hline Space types & $\begin{array}{l}\text { Majlees, Entrance } \\
\text { Hall, Sallah, } \\
\text { Dahrizes, Kitchen, } \\
\text { Store, Bath }\end{array}$ & Yes & $\begin{array}{l}\text { Majlees, Entrance } \\
\text { Hall, Sallah, } \\
\text { Dahrizes, Kitchen, } \\
\text { Store, Bath }\end{array}$ & Yes \\
\hline Spaces layout & Around the courtyard & Yes & Around inner Sallah & No \\
\hline Courtyard & Inner & Yes & Adjacent & No \\
\hline
\end{tabular}

\section{RESULTS}

First survey conducted among the young generation of female residents asked the following questions: (1) Would you like to improve the privacy in your residence, (2) Are you using your courtyard, (3) If yes, are you afraid of, (4) Are you curtaining your windows, (5) If yes, are you afraid of, (6) Are you using your roof terrace, (7) if yes, are you afraid of, (8) are you using your house terraces, balconies and (9) If yes, are you afraid of (Fig. 6).

The results of the survey demonstrate that the modern residence does not fully satisfy the privacy desires of the inhabitants: $93 \%$ of respondents are not satisfied $(1 \%$ - satisfied, $6 \%-$ are not sure about it) would like to have their residences improved (Chart 1). As shown by further results residences' privacy is largely maintained by the use of enclosed spaces and window curtains. The results of the second item show that only $27 \%(61 \%-$ no, 12 - sometimes) of respondents use the courtyard (Chart 2). The courtyard is exposed to the visitors $(28 \%)$, neighbours $(41 \%)$ and by-passers $(41 \%)$ and the residents are afraid of being overlooked (Chart 3). Most respondents (79\%) keep the windows curtained (13\% no, $8 \%$ - sometimes) because they are afraid of being observed by neighbours $(64 \%)$ and passers-by (36\%) (Charts 4 and 5). Additionally, the residents (66\%) consider that the 


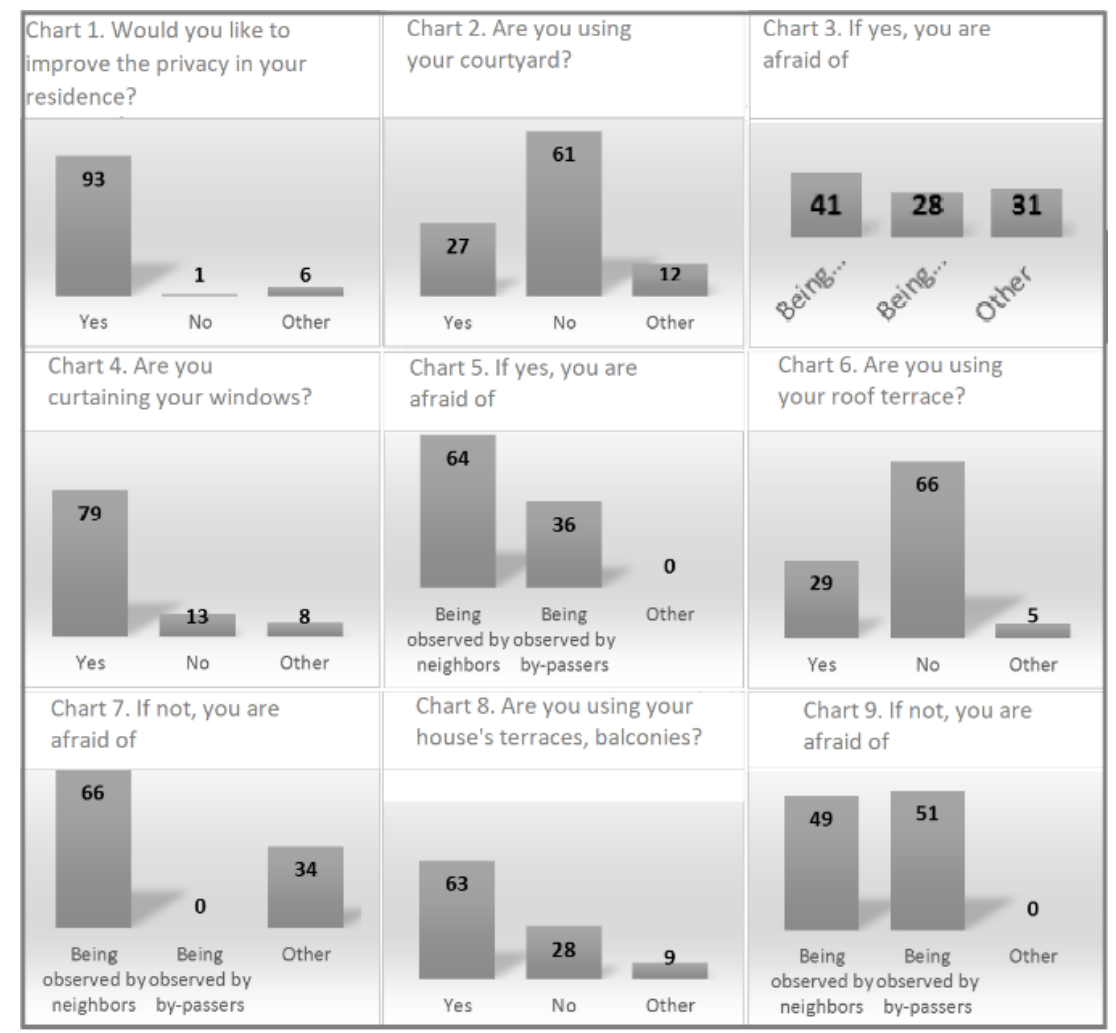

Figure 6: First survey, charts 1-9 demonstrate young female residents' satisfaction with residences' privacy.

neighbours overlook the roof terrace and, therefore, they are being observed (Charts 6 and $7)$. The balconies of the residences are used by $63 \%$ of the respondents $(28 \%-$ no, $9 \%-$ sometimes), though $49 \%$ of them consider that they are overlooked by the neighbours and $51 \%$ by-passers (Charts 8 and 9) (Fig. 6).

The second survey considers the opinion of the elderly female residents. The results show that 100 households participated in this survey house 211 female residents of age group from 35 and above (35-45: 43 residents; 45-55: 92; 55 and above: 76) (Chart 1) and 184 of them are living in modern residences, while 27 in traditional houses (Chart 2). The third item is composed of four questions and studies the level of privacy of the modern residences and inhabitants' satisfaction (Charts 3a, 3b, 3c and 3d). These results show that 19 residents cannot use the courtyard without being overlooked,134 of them are using the courtyard, but wearing an abaya (a loose over-garment, a long black dress, wore by Muslim women, which covers her head and veils her face), 31 of them are not using the courtyard at all (Chart 3a). Chart 3b shows that 176 of the participants achieve privacy from being observed by the neighbours and by-passers via curtaining the windows and only eight feel secure without curtaining the windows. Chart $3 \mathrm{c}$ demonstrates that none of the residents can use the roof terrace without being over-looked, 66 of them are using the roof terrace wearing an abaya and 118 are not using the terrace at all. Most of the respondents (82) are not satisfied with the privacy level, 67 are partially satisfied and 35 considers that the 
house's spaces are private (Chart $3 \mathrm{~d}$ ). The forth item examines the privacy offered by the old residences and inhabitants' satisfaction with it. Similarly, to the third item, is composed of four questions: usage of the courtyard, windows curtaining, usage of the roof terrace and satisfaction with the residence's privacy.

The results show that all 27 female inhabitants of the old residences are using the courtyard without being afraid of being seen by the neighbours or/and by-passers (Chart 4a). Chart $4 \mathrm{~b}$ shows that 20 (the majority) of the residents are not curtaining their windows (the windows face the courtyard and are not over-looked), four of them keep their windows closed and three of them have a different opinion. Chart $4 \mathrm{c}$ demonstrates that 18 of the residents consider the roof terrace private, five of them cannot use it without abaya and four residents are not using the terrace at all. Most of the residents (23) are satisfied with the privacy, only one is not satisfied and three consider that their residence partially satisfies their cultural demands for privacy (Chart 4d) (Fig. 7).

Both first and the second survey show that both young and elder generation of respondents are not satisfied with the privacy suggested by the modern house, therefore they cannot utilize the outdoor spaces and the indoor spaces' privacy is achieved through windows curtaining. On the other hand, a traditional house, as seen from the results, suggests higher degree of privacy to its inhabitants.

\section{DISCUSSIONS AND CONCLUSIONS}

In traditional Arab cities that are distinguished by their organic pattern, lack of open spaces and densely arranged housing units, the notion of privacy and hospitality has a significant influence on home culture and housing formation. This close relationship between culture, lifestyle and housing differentiates Islamic architecture from that of other cultures. Another distinguishing feature of Islamic architecture is the traditional courtyard community that is the customary residential form. Enclosed within the house's exterior walls and safeguarding the interior spaces, the courtyard extends the interior space, provides shade and protection against wind and sand and privacy to its inhabitants.

However, privacy concerns can limit designers' freedom and, therefore, contemporary architects often compromise it in favour of other principles such as aesthetics, modernism and construction cost. Furthermore, in private cultures such as in Arab Gulf countries, traditional houses built to adapt to the local natural habitat and to satisfy societal and cultural values are, for many (especially younger generations), are associated with limitations, hardship and a regressive past. The Arab city trying to catch up with the modernity, started losing that tight relationship between culture, lifestyle and housing and, subsequently, its uniqueness and the ability to meet its residents' cultural needs. As income and population continue to climb steadily in the Gulf countries, modern styled housing design, which values aesthetics, construction cost and modern technologies over cultural values, has become increasingly preferred over traditional architecture. As shown in Mirbat's case, the traditional courtyard house has been displaced by more modern structures. These structures are less able to offer subjective safety, which refers to the feeling of security (or, conversely, the absence of fear that cultural values are threatened). This research indicates that most modern houses in Mirbat use blinds or thick curtains to protect their privacy. Furthermore, the results of the surveys demonstrate that outdoor spaces are not used effectively because the inhabitants are afraid of being observed by neighbours or visitors, indoor and outdoor spaces cannot provide the inhabitants with their desired level of privacy, making them feeling insecure in their own homes. 


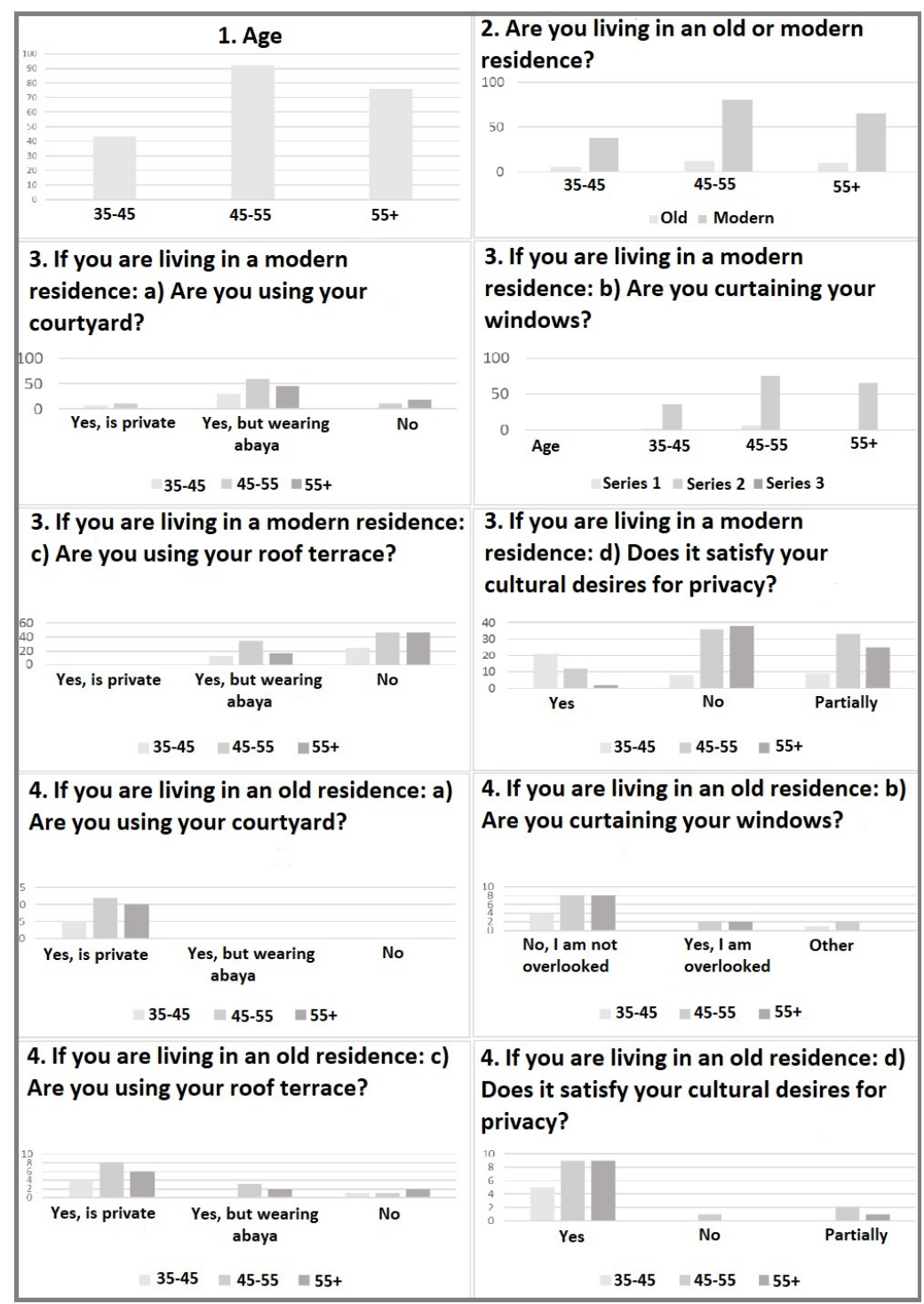

Figure 7: Second survey, charts 1-9 demonstrate elder generation female residents' satisfaction with residences' privacy.

This study's findings also support existing literature [26]-[30] in terms that for 'traditional house original cultural meaning preservation' a new design approach is required, which also incorporates innovations for comfort improvement while not compromising the privacy of the residents. Lessons learnt from traditional housing and residential satisfaction survey should be used for improving the performance of contemporary residences to maintain traditional housing private features but satisfies current needs of the residents. The results of this study show that by the employment of new construction materials and technologies, modern housing has eradicated limitations 
such as space and size, number of floors that existed in old traditional design and suggests comfortable conditions associated with a new style and a better life. However, while housing must certainly adapt to the rapidly changing society, contemporary designs, as seen from Mirbat's case, fails to capture private cultural traditions. Therefore, the survey conducted on modern residences' spatial use and residential satisfaction should be considered in housing design for private cultures and sets the base for further research that will take the next step of proposing a new experimental residential design.

\section{REFERENCES}

[1] Hegazy, S., The Omani architectural heritage: Identity and continuity. Proceedings of Second International Conference on Heritage and Sustainable Development, pp. 1341-1351, 2010.

[2] Nafeesi, A., Religious influence in architecture in the age of globalization: Case study in the Arab Gulf countries. Proceedings of Second International Conference: Workshop on Sustainable Architecture and Urban Design, 2012.

[3] Karimi, A. \& Hisseini, B., The influence of Iranian Islamic architecture on traditional houses of Kashan. Proceedings of the Second International Conference of Mikogawa Women's University, pp. 81-86, 2012.

[4] Cazacova, L., Traditional housing features shaped by the defensive city, case study M. PhD thesis, European University of Lefke, pp. 91-110, 110-226, 231-233, 2014.

[5] Yapicioglu, B. \& Cazacova, L., Omani Burqa' vs. decorated façade of modern Omani house: The case of Salalah, Dhofar Region, Oman. Academic Research Community Publications, pp. 101-111, 2019. DOI: 10.21625/archive.v2i3.350.

[6] Kabisch, S., Poessneck, J., Soeding, M. \& Schlink, U., Measuring residential satisfaction over time: Results from a unique long-term study of a large housing estate. Housing Studies, 2021. DOI: 10.1080/02673037.2020.1867083(2021).

[7] Abidin, N.Z., Abdullah, M.I., Basrah, N. \& Alias, M.N., Residential satisfaction: Literature review and a conceptual framework. IOP Conf. Series: Earth and Environmental Science, p. 385, 2019. DOI: 10.1088/1755-1315/385/1/012040.

[8] Mulholland Research and Consulting, Reception of privacy and density in housing. Report on research findings prepared for Popular Housing Group. Mulholland Research and Consulting: London, 2003. http://www.wellingborough.gov.uk/ download/downloads/id/3503/design_for_homes_popular_housing_research_2003. pdf. Accessed on: 16 Jul. 2017.

[9] Baessa, A. \& Hassan, A., An evaluation of space planning design in layout of the traditional house in Shibam, Yemen. Asian Culture and History, 2(2), pp. 15-24, 2010.

[10] Ibem, E., Opoko, A., Abeboye, A. \& Amole, D., Performance evaluation of residential buildings in public housing estates in Ogun state, Nigeria: Users'. Satisfaction Perspective. Frontiers of Architectural Research, 2, pp. 178-190, 2013.

[11] Xu, P., Feng-Shui models structured traditional Beijing courtyard houses. Journal of Architectural and Planning Research, 15(4), pp. 271-282, 1998.

[12] Aziz, A. \& Ahmad, A., Homemaking in a low-cost housing area. Procedia Social and Behavioural Science, 49, pp. 268-281, 2012.

[13] Susilo, I., The living culture and typo-morphology of vernacular-traditional houses in Kerala. Journal of the International Society for the Study of Vernacular Settlement ISVS e-Journal, 2(4), 2013. 
[14] Mohareb, N., Searching for urban patterns; an assessment of historic edges and its surrounding context: Historic Cairo as case of study. Archnet-IJAR, 10(2), pp. 67-89, 2016.

[15] Poirier, V., Piche, D. \& Casault, A., Studying the informal as a strategy for improving housing in poor neighbourhoods of the Senegalese City. Proceedings of 6th International Seminar on Vernacular Settlements, Contemporary Vernaculars: Places, Processes and Manifestations, pp. 124-135, 2012.

[16] Hosseini, E., Musrib, G. \& Nadifa, R., Design values in traditional architecture: Malay house. Proceedings of 6th International Seminar on Vernacular Settlements, Contemporary Vernaculars: Places, Processes and Manifestations, pp. 308-318, 2012.

[17] Benkari, N., The defensive vernacular settlements in Oman: A contextual study. International Journal of Heritage Architecture, 1(2), pp. 175-184, 2017.

[18] Gwandure, C., Life with limited privacy due to housing challenges: Impact on children's psychological functioning. African Safety Promotion: A Journal of Injury and Violence Prevention, 7(1), pp. 30-49, 2009. DOI: 10.4314\%2Fasp. 7i1.54601.

[19] European Court of Human Rights, European convention of human rights. Strasbourg, European Council of Human Rights 1950, Article 8, 10. https://www.echr.coe.int/ documents/convention_eng.pdf. Accessed on: 11 Mar. 2016.

[20] Jiboye, A., Post-occupancy evaluation of residential satisfaction in Lagos, Nigeria: Feedback for residential improvement. Frontiers of Architectural Research, 1, pp. 236-243, 2012.

[21] Mohit, M. \& Azim, M. Assessment of residential satisfaction with public housing in Hulhumake, Maldives. Procedia Social and Behavioural Science, 50, pp. 756-770, 2012.

[22] Ahmed, H., Edwards, D.J., Lai, J.H.K., Roberts, C., Debrah, C., Owusu-Manu, D.-G. \& Thwala, W.D., Post occupancy evaluation of school refurbishment projects: Multiple case study in the UK. Buildings, 11, p. 169, 2021.

DOI: 10.3390/buildings11040169.

[23] Bunster, V. \& Bustamante, W., Structuring a residential satisfaction model for predictive personalization in mass social housing. Sustainability, 11, p. 3943, 2019. DOI: $10.3390 /$ su11143943.

[24] Mohareb, N. \& Kronenburg, R., Spatial analysis of urban edges in Arab historic walled cities: Alexandria as a case study. Planning Perspectives: An International Journal of History Planning and the Environment, 27(3), pp. 439-452, 2012.

[25] Dhofar Municipality, Building Regulation for Dhofar Province. Office of Minister of State \& Governor of Dhofar: Dhofar, 1996. Local Order no. 2/96 Issued on sixth Rabial $11.1417 \mathrm{H}$.

[26] Almansuri, A., Curwell, S. \& Dowdle, D., Designing a dwelling unit in Tripoli, Libya by using sustainable architecture principles. Proceedings of the Seventh International Conference on Sustainable Architecture and Urban Development IV, pp. 79-97, 2010.

[27] Wright, G., Tower and slab: Histories of global mass housing, Abingdon: Routledge (book review). Planning Perspectives: An International Journal of History, Planning and the Environment, 27(3), pp. 494-495, 2012.

[28] Nafeesi, A., Religious influence in architecture in the age of globalization: Case study in the Arab Gulf countries. Proceedings of Second International Conference: Workshop on Sustainable Architecture and Urban Design, 2012. 
422 The Sustainable City XV

[29] Eldemery, I., Globalization challenges in architecture. Journal of Architectural and Planning Research, 2(4), pp. 343-354, 2009.

[30] Ragette, F., Traditional Architecture of the Arab Region, American University of Sharjah: UAE, pp. 255-257, 2006. 